\title{
A Dual Reporter lodinated Labeling Reagent for Cancer Positron Emission Tomography Imaging and Fluorescence-Guided Surgery
}

Zhi Lu, ${ }^{*},{ }^{\dagger} \S$ Truc Thuy Pham, ${ }^{\S}$ Vineeth Rajkumar, ${ }^{\ddagger}$ Zilin Yu, ${ }^{\S}$ R Barbara Pedley, ${ }^{\ddagger}$ Erik Årstad, ${ }^{\text {II }}$ John Maher, $\#, \perp, \|$ and Ran Yan* ${ }^{*} \S(0)$

${ }^{\dagger}$ Department of Nuclear Medicine, First Affiliated Hospital of Dalian Medical University, Dalian 116020, People’s Republic of China

${ }^{\S}$ School of Imaging Sciences and Biomedical Engineering, King's College London, St. Thomas' Hospital, London SE1 7EH, United Kingdom

${ }^{\ddagger}$ UCL Cancer Institute, University College London, 72 Huntley Street, London WC1E 6BT, United Kingdom

II Institute of Nuclear Medicine and Department of Chemistry, University College London, 235 Euston Road (T-5), London NW1 2BU, United Kingdom

${ }^{\#}$ School of Cancer and Pharmaceutical Studies, Guy's Hospital, King's College London, Third Floor Bermondsey Wing, Great Maze Pond, London SE1 9RT, United Kingdom

${ }^{\perp}$ Department of Immunology, Eastbourne Hospital, Kings Drive, Eastbourne, East Sussex BN21 2UD, United Kingdom

"Department of Clinical Immunology and Allergy, King's College Hospital NHS Foundation Trust, Denmark Hill, London SE5 9RS, United Kingdom

Supporting Information

ABSTRACT: The combination of early diagnosis and complete surgical resection offers the greatest prospect of curative cancer treatment. An iodine-124/fluorescein-based dual-modality labeling reagent, ${ }^{124} \mathrm{I}-\mathrm{Green}$, constitutes a generic tool for one-step installation of a positron emission tomography (PET) and a fluorescent reporter to any cancerspecific antibody. The resulting antibody conjugate would allow both cancer PET imaging and intraoperative fluorescence-guided surgery. ${ }^{124}$ I-Green was synthesized in excellent radiochemical yields of $92 \pm 5 \%(n=4)$ determined by HPLC with an improved one-pot three-component radioiodination

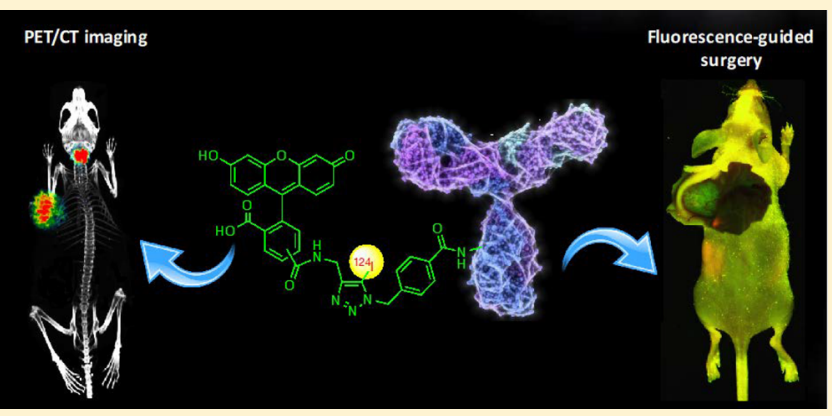
reaction. The A5B7 carcinoembryonic antigen (CEA)-specific antibody was conjugated to ${ }^{124} \mathrm{I}$-Green. High tumor uptake of the dual-labeled A5B7 of $20.21 \pm 2.70,13.31 \pm 0.73$, and $10.64 \pm$ $1.86 \% \mathrm{ID} / \mathrm{g}$ was observed in CEA-expressing SW1222 xenograft mouse model $(n=3)$ at 24,48 , and 72 h post intravenous injection, respectively. The xenografts were clearly visualized by both PET/CT and ex vivo fluorescence imaging. These encouraging results warrant the further translational development of ${ }^{124} \mathrm{I}$-Green for cancer PET imaging and fluorescence-guided surgery.

\section{INTRODUCTION}

Cancer is a leading cause of death worldwide, accounting for 8.8 million deaths in 2015. About 14 million people are diagnosed with cancer each year, and this figure is expected to reach 27 million by 2030 according to the World Health Organization. ${ }^{1}$ The combination of early diagnosis and complete surgical removal represents the most effective therapeutic modality for malignant tumors. ${ }^{2}$

Positron emission tomography (PET) is a functional imaging technique. By targeting cancer-associated biochemical variations at the molecular level, this imaging modality can detect tumors at the earliest stages of malignancy. Currently, the 2deoxy-2- $\left[{ }^{18} \mathrm{~F}\right]$ fluoro-D-glucose $\left({ }^{18} \mathrm{~F}-\mathrm{FDG}\right)$ based PET/CT scan is routinely used for the diagnosis and prognostic assessment of cancer patients. ${ }^{3}$ However, ${ }^{18}$ F-FDG is not cancer-specific.
Benign diseases such as inflammation or infection are also associated with increased ${ }^{18}$ F-FDG uptake, resulting in falsepositive diagnosis. ${ }^{4}$ ImmunoPET employing positron emitterlabeled tumor-specific monoclonal antibodies has shown great promise to stage cancer patients and detect tiny tumor lesions in several clinical trials thanks to their nanomolar binding affinity and specificity for tumor-associated biomarkers. ${ }^{5}$ Zirconium-89 (23\% $\beta^{+}, T_{1 / 2}=3.3$ days $)$ and iodine-124 $\left(24 \% \beta^{+}, T_{1 / 2}=4.2\right.$ days $)$ are the most commonly used positron emitters in immunoPET due to their longer half-lives that are compatible with the biological half-lives of the full-size antibodies. ${ }^{6}$ In a feasibility study, ${ }^{89} \mathrm{Zr}$-trastuzumab targeting

Received: November 28, 2017

Published: February 1, 2018 
Scheme 1. Synthesis of the Dual PET and Fluorescent Labeling Reagent, ${ }^{124} \mathrm{I}-\mathrm{Green}{ }^{a}$

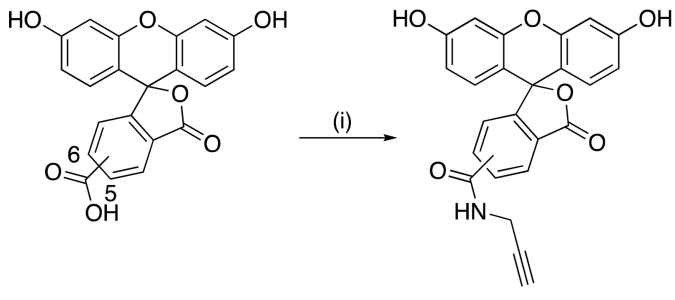

[1]

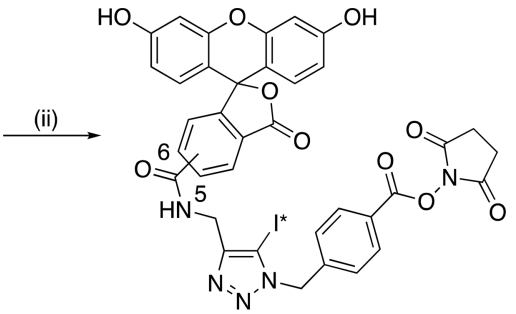

${ }^{124}$ I-Green

${ }^{a}(\mathrm{i})$ propargylamine, propylphosphonic anhydride, DIPEA, DMF, $0{ }^{\circ} \mathrm{C}$ to rt, $18 \mathrm{~h}, 30 \%$; (ii) (a) CuI, TEA, 4-azidomethyl- $\mathrm{N}$-succinimidyl benzoate, NIS, DMF, $18 \mathrm{~h}, 37 \%$ when $\mathrm{I}^{*}={ }^{127} \mathrm{I}$, or $(\mathrm{b}) \mathrm{CuCl}_{2}$, TEA/TEA $\cdot \mathrm{HCl}$, bathophenanthroline $(10 \mathrm{~mol} \%)$, 4-azidomethyl- $\mathrm{N}$-succinimidyl benzoate, $\left[{ }^{124} \mathrm{I}\right] \mathrm{NaI}, \mathrm{DMF} / \mathrm{CH}_{3} \mathrm{CN} / \mathrm{H}_{2} \mathrm{O}, 90 \mathrm{~min}$ when $\mathrm{I}^{*}={ }^{124} \mathrm{I}$.

Table 1. Optimization of the Radioiodination of the Dual Labeling Reagent

\begin{tabular}{llc} 
entry $^{a}$ & \multicolumn{1}{c}{ ligand $(10 \mathrm{~mol} \%)$} & temperature $\left({ }^{\circ} \mathrm{C}\right)$ \\
$\mathbf{1}$ & N/A & $\mathrm{rt}$ \\
$\mathbf{2}$ & N/A & 60 \\
3 & 1,10-phenanthroline & $\mathrm{rt}$ \\
4 & 4,7-dichloro-1,10-phenanthroline & $\mathrm{rt}$ \\
$\mathbf{5}$ & 4,7-dimethoxy-1,10-phenanthroline & $\mathrm{rt}$ \\
$\mathbf{6}$ & bathophenanthroline & $\mathrm{rt}$ \\
7 & bathophenanthroline $(50$ mol \%) & $\mathrm{rt}$ \\
$\mathbf{8}$ & bathophenanthroline & $\mathrm{rt}$ \\
$\mathbf{9}^{c}$ & bathophenanthroline & $\mathrm{rt}$ \\
$\mathbf{1 0}^{c, d}$ & bathophenanthroline & $\mathrm{rt}$
\end{tabular}

$\begin{array}{cc}\text { time }(\mathrm{min}) & \mathrm{RCY}(\%)^{b} \\ 90 & 4 \\ 90 & 40 \\ 90 & 75 \pm 10(n=3) \\ 90 & 58 \\ 90 & 40 \\ 90 & 41(n=6) \\ 90 & 66 \\ 60 & 25 \\ 90 & 92 \pm 5(n=4) \\ 90 & 59\end{array}$

${ }^{a}$ Suspension of $N$-propargyl-5(6)-carboxyfluoresceinamides $(1.0 \mu \mathrm{mol}), \mathrm{CuCl}_{2}(1.0 \mu \mathrm{mol})$ TEA (1.5 $\left.\mu \mathrm{mol}\right)$ and ligand (mol \%) was added to a mixture of azidomethyl-N-succinimidyl benzoate $(1.0 \mu \mathrm{mol})$ and $\left[{ }^{125} \mathrm{I}\right] \mathrm{NaI}(6 \mu \mathrm{L}) .{ }^{b}$ Radiochemical yield was determined by $\mathrm{HPLC}$. ${ }^{c}\left[{ }^{124} \mathrm{I}\right] \mathrm{NaI}$ was used for the reaction. ${ }^{d}$ TEA. $\mathrm{HCl}$ was used to neutralize the $\mathrm{NaOH}$ in the aqueous $\left[{ }^{124} \mathrm{I}\right] \mathrm{NaI}$.

the human epidermal growth factor receptor 2 (HER2) allowed PET imaging of most of the known tumors including brain lesions in 14 patients with HER2-positive metastatic breast cancer. ${ }^{7}$ Meanwhile, ${ }^{124}$ I-girentuximab targets the cell-surface carbonic anhydrase IX that is homogeneously overexpressed in more than $95 \%$ of clear cell renal cell carcinoma (ccRCC). It showed superior sensitivity and specificity for detecting ccRCC compared to the contrast-enhanced CT scanning in a multicenter trial involving 195 patients. $^{8}$

Once cancer patients are recommended for surgery, the surgeon faces the challenge of pinpointing the exact sites of tumor lesions and identifying the metastatic lymph nodes for resection. To increase the accuracy of tumor delineation, Larson et al. successfully applied ${ }^{124}$ I-girentuximab to the preoperative mapping with PET and intraoperative localization of ccRCC with a hand-held PET probe capable of measuring both $\gamma$ and $\beta$-emission. ${ }^{9}$ However, due to the limited spatial resolution of the hand-held radiation detection device, it is challenging to distinguish the surgical margins and to identify the interface between the tumor and the surrounding healthy tissues. In contrast, fluorescence imaging offers superior spatial resolution. Ntziachristos et al. demonstrated that a folate receptor-targeting fluorescein molecular probe offered specific and sensitive real-time identification of tumor deposits with clear surgical margins during fluorescence-guided surgery in ovarian cancer patients. ${ }^{10}$

To harness the synergistic property of PET and fluorescence imaging for cancer diagnosis and precise tumor resection, considerable effort has been made to develop dual PET and fluorescence imaging reagents. ${ }^{11-13}$ However, none of these has been approved by the Food and Drug Administration (FDA). ${ }^{12}$
One limiting factor is the lack of a generic method to prepare these reagents for screening. ${ }^{13}$ We envisage that a dual PET and fluorescent labeling reagent would act as a generic tool to install both a PET and a fluorescent reporter to any cancer targeting antibody. Thus, it would standardize the preparation protocol, accelerate the screening process, and minimize the translational hurdle.

Recently, we reported a copper-mediated one-pot threecomponent radioiodination method that allowed the reaction of functionalized alkynes, azides, and radioactive iodine-125 $(\gamma$, $T_{1 / 2}=60$ days) to form trisubstituted iodotriazoles. ${ }^{14,15}$ To explore the potential of this chemistry in combinational cancer diagnosis and surgery, we have synthesized a new dual modality labeling reagent, ${ }^{124}$ I-Green. It is equipped with (i) a positron emitter, iodine-124, for PET imaging of cancer, (ii) a clinically approved green fluorescent reporter, fluorescein, for fluorescence-guided surgery, and (iii) a succinimide moiety for antibody coupling (Scheme 1). Here, we exemplify the utility of this approach to allow the one-step installation of a dual PET and fluorescence reporter to a carcinoembryonic antigen (CEA) specific murine antibody A5B7. The dual labeled A5B7 offered excellent tumor-to-background contrast in both $\mathrm{PET} / \mathrm{CT}$ and ex vivo fluorescence imaging.

\section{RESULTS}

Synthetic Chemistry and Radiolabeling. Initially, 5(6)carboxyfluorescein was treated with $N, N$-diisopropylethylamine in DMF to form the corresponding lactone and then reacted the carboxylic group with propargylamine using propylphosphonic anhydride as the coupling reagent at $0{ }^{\circ} \mathrm{C}$ to form the $\mathrm{N}$-propargyl-5(6)-carboxyfluoresceinamide in 30\% yield. The 4- 

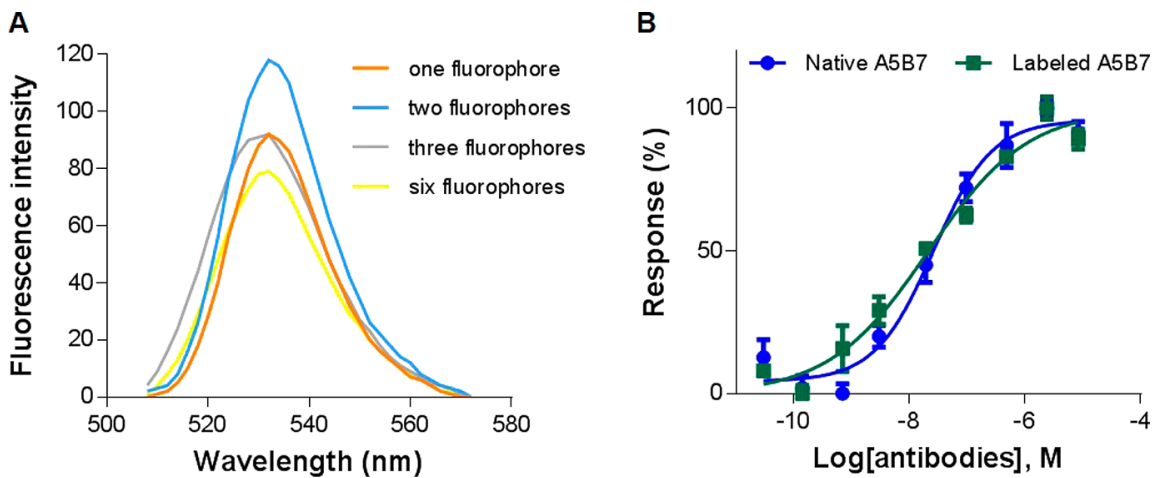

Figure 1. Fluorescence intensity of the dual labeled A5B7 $(50 \mu \mathrm{g})$ with 1, 2, 3, or 6 fluorophores per antibody. Data are representative of three independent replicates (A). ELISA analysis to determine the $\mathrm{EC}_{50}$ of the dual labeled $\mathrm{A} 5 \mathrm{~B} 7$ with two fluorophores per antibody and the native $\mathrm{A} 5 \mathrm{~B} 7$ (mean $\pm \mathrm{SD}, n=3$ independent replicates) (B).
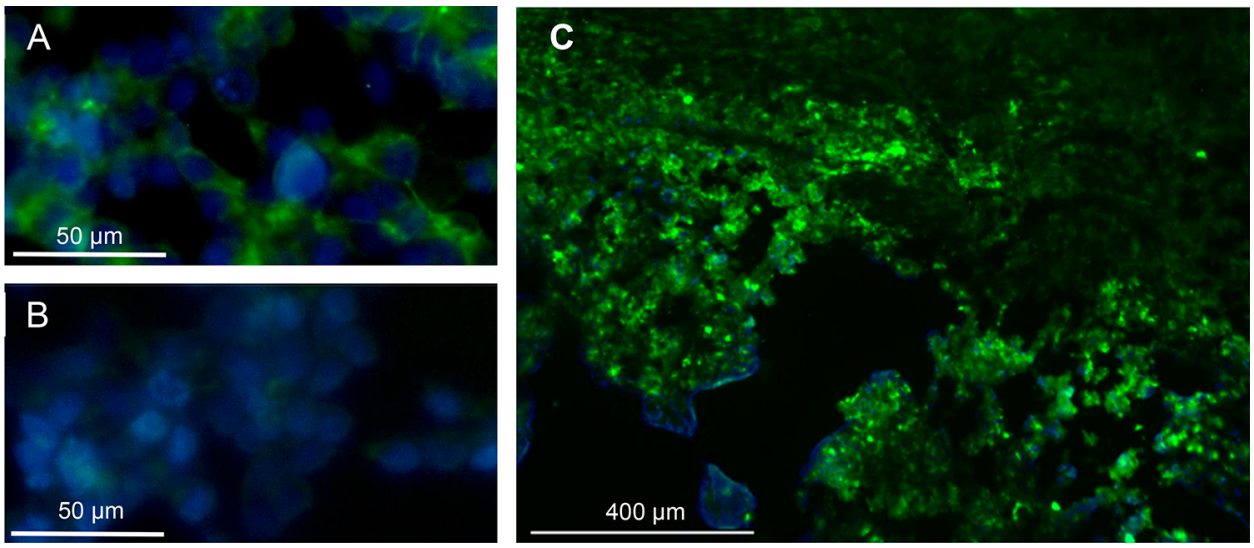

Figure 2. Fluorescence images of SW1222 cells stained with the dual labeled A5B7 antibody and bisbenzimide H 33342, without (A) and with blocking using the native A5B7 (B) in vitro. Fluorescence image of an SW1222 tumor xenograft section stained with the dual labeled A5B7 antibody and the bisbenzimide $\mathrm{H} 33342$ in vitro (C).

azidomethyl-N-succinimidyl benzoate was also prepared following a literature method in two steps with an overall of yield $61 \% .{ }^{14}$ Subsequently, the nonradioactive reference compound of ${ }^{124} \mathrm{I}$-Green was synthesized from the reaction of $\mathrm{N}$-propargyl-5(6)-carboxyfluoresceinamide, 4-azidomethyl- $\mathrm{N}$ succinimidyl benzoate, and $N$-iodosuccinimide in the presence of copper(I) iodide in DMF with a moderate yield of $37 \%$ (Scheme 1.). Next, we systematically screened different conditions to optimize the radiochemical preparation of ${ }^{124} \mathrm{I}$ Green. $\left[{ }^{125} \mathrm{I}\right] \mathrm{NaI}$ was used as the surrogate of $\left[{ }^{124} \mathrm{I}\right] \mathrm{NaI}$ for the optimization of the radiolabeling. Under the previously published conditions, low radiochemical yields (RCYs) of $4 \%$ and $40 \%$ measured by HPLC were observed at room temperature (rt) and $60{ }^{\circ} \mathrm{C}$, respectively (Table 1 , entries 1 and 2). Screening of 1,10-phenanthroline copper ligands revealed bathophenanthroline to be optimal for the reaction and provided the ${ }^{125}$ I-labeled target compound in excellent RCYs of $91 \pm 4 \%$ measured by HPLC $(n=6)$ (Table 1 , entry $6)$. When these optimized conditions were applied to the ${ }^{124} \mathrm{I}$ radiolabeling, excellent RCYs of $92 \pm 5 \%(n=4)$ measured by HPLC were achieved in the presence of TEA.HCl (Table 1 , entry 10, and Supporting Information, Figure S1). The identity of ${ }^{124} \mathrm{I}$-Green was proved by co-eluting with its nonradioactive reference compound (Supporting Information, Figure S2). When prepared under the optimized conditions starting with around $36 \mathrm{MBq}$ of $\left[{ }^{124} \mathrm{I}\right] \mathrm{NaI},{ }^{124} \mathrm{I}-\mathrm{Green}$ was isolated in radioactivity yields of $78 \pm 6 \%(n=3)$ with the radiochemical purity $\geq 95 \%$ (Supporting Information, Figure S2) and the molar activity around $3.5 \mathrm{GBq} / \mu \mathrm{mol}$.

Dual Labeling Reagent Antibody A5B7 Conjugation and Characterization. Next, we conjugated ${ }^{124} \mathrm{I}$-Green with a murine CEA specific antibody A5B7. The A5B7 was incubated with ${ }^{124}$ I-Green in $10 \mathrm{mM}$ pH 9.0 carbonate buffer at $\mathrm{rt}$ for 45 min. Good labeling efficiency of $60 \pm 5 \%(n=3)$ was achieved (Supporting Information, Table S1, entry 1) after size exclusion column purification. The recovery efficiency of ${ }^{124} \mathrm{I}$-Green A5B7 conjugate from this size exclusion column was also determined as $80 \pm 4 \%(n=3)$ by passing the purified ${ }^{124} \mathrm{I}$ Green labeled A5B7 conjugate through a new size exclusion column. To determine the optimal number of fluorophores per antibody, we co-incubated the A5B7 with a mixture of ${ }^{124} \mathrm{I}$ Green and different amount of the nonradioactive reference compound in $2,5,10$, and 20 equiv of the antibody in $10 \mathrm{mM}$ $\mathrm{pH} 9.0$ carbonate buffer at $\mathrm{rt}$ for $45 \mathrm{~min}$. The radiolabeling efficiencies were approximately $45 \%, 34 \%, 27 \%$, and $25 \%$ ( $n=$ $3)$, respectively. The average fluorophore per antibody was then determined as $1,2,3$, or 6 , respectively (corrected for the loss of ${ }^{124} \mathrm{I}$-Green A5B7 conjugate on the size exclusion column) (Supporting Information, Table S1 entries 2-5). Subsequently, the fluorescence intensity of the dual labeled A5B7 $(50 \mu \mathrm{g})$ with $1,2,3$, or 6 fluorophores per antibody was measured from 508 to $572 \mathrm{~nm}$ with an excitation wavelength at $460 \mathrm{~nm}$. The dual labeled A5B7 with two fluorophores per antibody emitted the strongest fluorescence between 526 and $572 \mathrm{~nm}$ (Figure 
1A) and was therefore selected for further evaluation. HPLC analysis using a size exclusion column revealed comparable retention times for the dual labeled A5B7 conjugate (8.61 min) and native A5B7 (8.55 $\mathrm{min})$. The absence of other peaks in the HPLC chromatogram suggests that labeling and purification were achieved without causing antibody aggregation (Supporting Information, Figure S3). To assess whether the dual labeled A5B7 preserved its binding affinity, we carried out an enzymelinked immunosorbent assay (ELISA) to measure the halfmaximal effective concentration $\left(\mathrm{EC}_{50}\right)$ of the dual labeled and the native A5B7 to the CEA. The absorbance of the dual labeled A5B7 was very close to the native antibody at all nine concentrations (Figure 1B), and its $\mathrm{EC}_{50}$ was determined as $21.12 \pm 1.20 \mathrm{nM}$, which is similar to the native A5B7 (26.00 \pm $1.13 \mathrm{nM})(n=3)$.

In Vitro Biological Evaluation of the Dual Labeled A5B7. The dual labeled A5B7 $(7 \mu \mathrm{g} / \mathrm{mL})$ was incubated with the CEA-expressing human colorectal carcinoma SW1222 cells at $37^{\circ} \mathrm{C}$ for $1 \mathrm{~h}$ followed by bisbenzimide $\mathrm{H} 33342$ for $5 \mathrm{~min}$. Bright-green fluorescence from the stained SW1222 cells was observed under a fluorescence microscope (Figure 2A). When co-incubated with the native antibody $(39 \mu \mathrm{g} / \mathrm{mL})$, cellular uptake of the dual labeled A5B7 was largely blocked (Figure 2B). Next, the dual labeled A5B7 was incubated with the fixed SW1222 xenograft tissue sections at rt for $30 \mathrm{~min}$ followed by bisbenzimide $\mathrm{H} 33342$ for $5 \mathrm{~min}$. Once again, strong and sustained green fluorescence was observed from the xenograft tissue sections (Figure $2 \mathrm{C}$ ).

Biodistribution Study, PET/CT, and Ex Vivo Fluorescence Imaging. The biodistribution of ${ }^{124} \mathrm{I}$-Green dual labeled A5B7 in SW1222 tumor xenograft-bearing CD1 nude mice $(n=$ 3 per time point) was measured at 24,48 , and $72 \mathrm{~h}$ post-iv injection (Figure 3). Higher radioactivity accumulation was

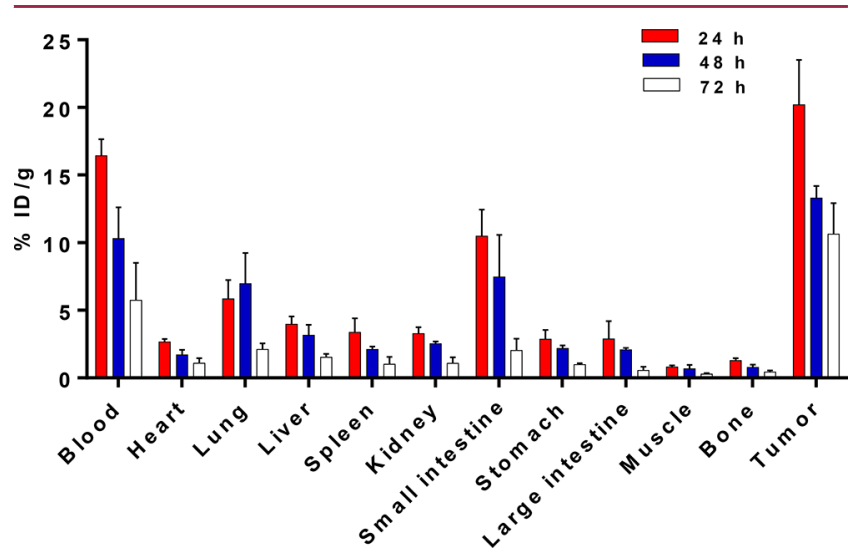

Figure 3. Biodistribution of the ${ }^{124} \mathrm{I}$-Green dual labeled A5B7 in the SW1222 tumor xenograft-bearing CD1 nude mice at 24, 48, and $72 \mathrm{~h}$ post-iv injection (mean $\pm \mathrm{SD}, n=3$ mice per time point).

observed in the tumor, blood, and small intestine compared to other organs. Tumor uptake was $20.21 \pm 2.70,13.31 \pm 0.73$, and $10.64 \pm 1.86$ percentage injected dose per gram tissue $(\%$ $\mathrm{ID} / \mathrm{g}$ ) at these three time points, respectively (Supporting Information, Table S2). Uptake in the blood and small intestine was $16.42 \pm 1.01$ and $10.50 \pm 1.59 \% \mathrm{ID} / \mathrm{g}$, respectively, at $24 \mathrm{~h}$, and rapidly decreased to $5.74 \pm 2.27$ and $2.02 \pm 0.73 \% \mathrm{ID} / \mathrm{g}$, respectively, at $72 \mathrm{~h}$ post injection (Supporting Information, Table S2).

Next, the ${ }^{124}$ I-Green dual labeled A5B7 in PBS was intravenously injected into CD1 nude mice $(n=3)$ bearing an established SW1222 tumor xenograft in the front-left flank area. Animals were imaged in three sequential $60 \mathrm{~min}$ PET/CT scans, performed at 24,48 , and $72 \mathrm{~h}$ post injection. The SW1222 tumor xenografts were clearly visualized in the 3D PET/CT images at all three time points, although distribution of the radioactivity signals within the tumors was heterogenious (Figure 4A,B). Weaker radioactivity signals in the hearts were observed at 24 and $48 \mathrm{~h}$ but were cleared in $72 \mathrm{~h}$ PET/CT image (Figure 4B). Quantification of radioactivity level in selected organs including tumor, liver, and kidney was largely consistent with the biodistribution data (Supporting Information, Figure S4). As expected, accumulation of ${ }^{124} \mathrm{I}$ in the thyroid glands was also detected and the radioactivity levels were quantified as $32.25 \pm 3.24,33.22 \pm 1.09$, and $36.92 \pm$ $5.19 \% \mathrm{ID} / \mathrm{mL}$ at 24,48 , and $72 \mathrm{~h}$ post injection, respectively (Supporting Information, Figure S4).

All three animals were sacrificed at the end of the last PET/ CT scan, and the SW1222 tumor xenografts were exposed. When observed in a whole-body fluorescence imaging system with an excitation wavelength of $460 \mathrm{~nm}$, the xenografts were clearly visualized and distinguished from the surrounding tissue (Figure 5A). As a result, complete resection of the tumor was feasible (Figure 5B). The strength of fluorescence emission from the xenografts was compared with other major thoracoabdominal organs. Apart from the stomach and the large intestine, the tumor xenografts showed the strongest fluorescence (Figure 5C,D).

Ex Vivo Sequential Autoradiography and Fluorescence Imaging. Three tumor sections of a SW1222 xenograft resected from a mouse post the PET/CT imaging were exposed to a phosphor screen for 3 days. After scanning on a phosphor imager, autoradiography demonstrated the uneven distribution of the radioactivity in each tumor section (Figure 6A). The same tumor sections where then analyzed for fluorescence on the same imager using the fluorescein filter. The distribution and the intensity of fluorescence emission largely co-registered with the radioactivity signals in the autoradiograph of the corresponding tumor sections (Figure 6B).

\section{DISCUSSION AND CONCLUSION}

Biomedical imaging is an essential contributor to cancer patient management that provides vital information required for cancer staging, therapeutic planning, and the monitoring of disease status. ${ }^{17}$ Multimodality imaging techniques can overcome the limitations of each imaging modality and supply complementary information to improve cancer care. PET and fluorescence imaging are highly synergistic. ${ }^{12,13}$ The former can provide quantitative measurement without limitation of penetration depth, while the latter offers superior spatial resolution. A cancer-specific dual PET and fluorescence imaging reagent labeled with a longer half-life radioisotope such as ${ }^{124} \mathrm{I}\left(T_{1 / 2}=\right.$ 4.2 days) could enable the cancer surgical treatment to adopt a highly integrated approach. PET/CT imaging of the malignant lesions would enable more accurate preoperative surgical planning. During surgery, the tumors and the metastatic lymph nodes, especially the deep-lying deposits, could then be rapidly localized with a hand-held radiation detector. Subsequently, fluorescence imaging would "light up" these tumors for real-time assessment and more accurate resection.

To prepare our dual PET and fluorescent labeling reagent, we chose the FDA approved fluorescein as the fluorescent reporter because it has successfully been used in fluorescenceguided surgery in clinical trials. ${ }^{10}$ The nonradioactive reference 


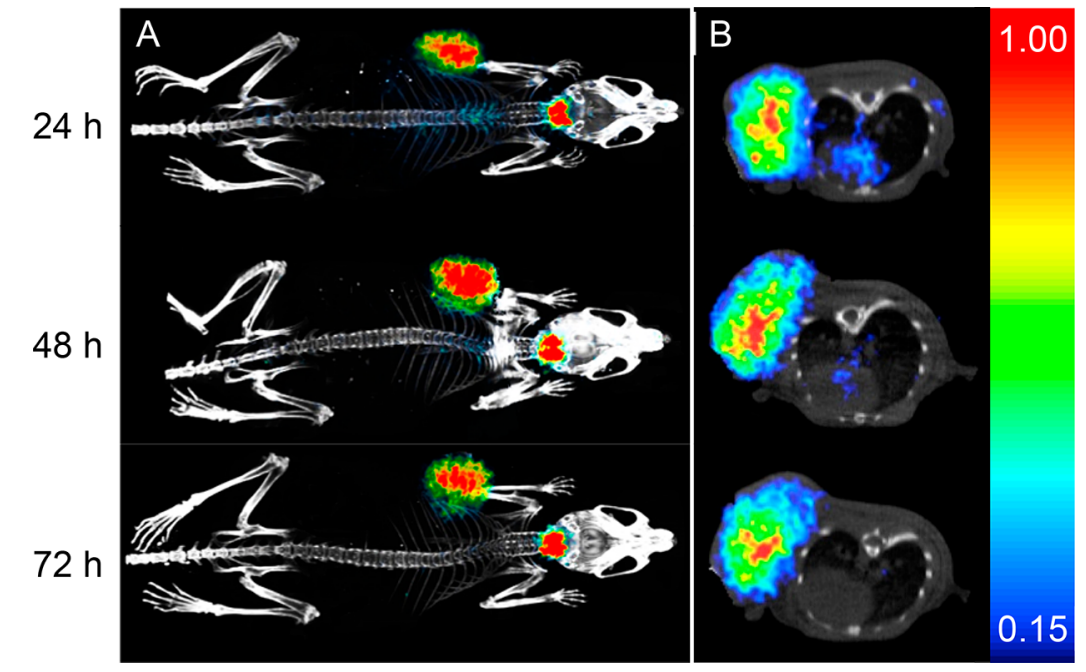

Figure 4. Sequential 3D (A) and the corresponding axial (B) PET/CT images of a representative CD1 nude mouse bearing an SW1222 tumor xenograft in the front-left flank. Mice received ${ }^{124} \mathrm{I}$-Green dual labeled A5B7 and were imaged at 24, 48, and $72 \mathrm{~h}$ post-iv injection. Data are representative of images obtained in three mice at these time points.
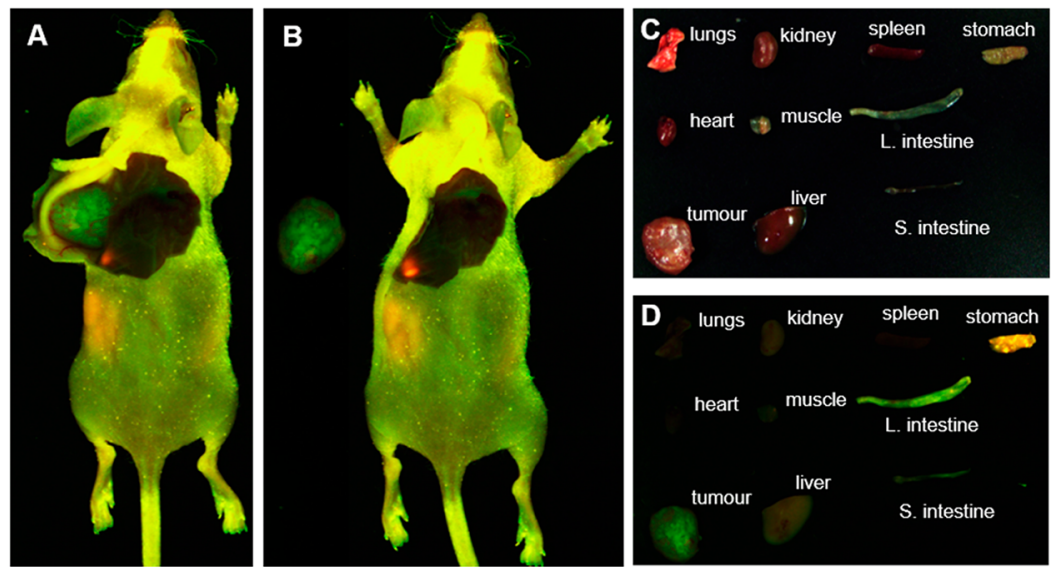

Figure 5. Ex vivo fluorescence images of a representative CD1 nude mouse bearing an SW1222 tumor xenograft in the front-left flank. Animals received the ${ }^{124} \mathrm{I}$-Green dual labeled A5B7 and was imaged at $72 \mathrm{~h}$ post-iv injection before (A) and after complete tumor resection (B). The resected tumor and major thoracoabdominal organs are shown under white-field view (C) and fluorescence-field view (D). Data are representative of three mice.

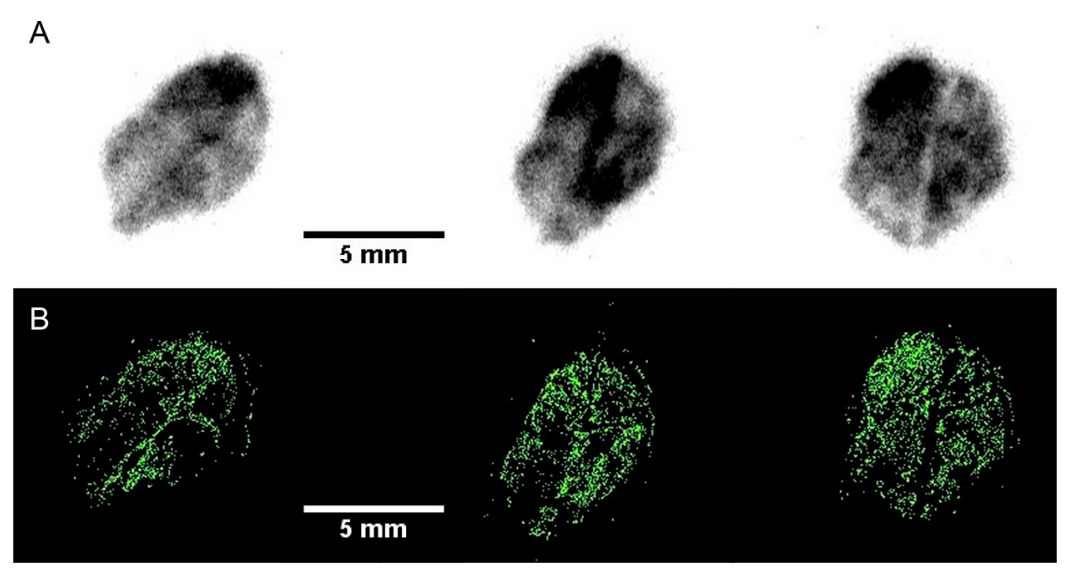

Figure 6. Ex vivo autoradiography of three SW1222 tumor xenograft tissue sections (A) and their corresponding fluorescence images (B). Data are representative of three tumor sections.

compound of ${ }^{124} \mathrm{I}$-Green was synthesized in a moderate yield of $37 \%$. The 5(6)-carboxyfluorescein regioisomer mixture was used for this proof-of-concept study due to its low cost relative to the pure 5 or 6 regioisomers. The mixture has similar chemical and photophysical properties as any of the single regioisomer, and once coupled with an antibody the 
pharmacokinetics of the conjugate will, in any case, be dominated by the macromolecule. Next, we optimized the radiosynthesis of ${ }^{124} \mathrm{I}$-Green. Iodine-125 was used as a surrogate of iodine-124 $\left(\gamma_{\max } 35 \mathrm{keV}\right.$ vs $1691 \mathrm{keV}$ for $\left.{ }^{124} \mathrm{I}\right)$ for the development work to reduce the cost of the screening and to minimize ionizing radiation exposure. Poor RCYs of the dual labeling reagent were initially obtained when applying the previously published conditions for the formation of radioiodinated 1,2,3-triazoles. ${ }^{14,15}$ As a phenanthroline analogue has been reported to accelerate the copper-mediated alkyne-azide "click" reactions, ${ }^{18}$ we screened structurally related ligands and found that addition of bathophenanthroline was beneficial for the radiochemical reaction. Using this ligand, ${ }^{124} \mathrm{I}$-Green was obtained with excellent RCYs around 92\% determined by HPLC.

To explore the application of ${ }^{124} \mathrm{I}-\mathrm{Green}$ to cancer PET imaging and fluorescence-guided surgery, we selected a CEAspecific murine monoclonal antibody A5B7, a CEA-expressing SW1222 human colorectal cell line, and the corresponding tumor xenograft to systematically evaluate this dual modality imaging approach in vitro and in vivo. The specific binding of the directly labeled ${ }^{131}$ I-A5B7 to the SW 1222 cells and derived xenografts is well documented in the literature. ${ }^{16,19}$ Furthermore, ${ }^{131}$ I-A5B7 has been employed in several clinical trials for radioimmunotherapy of metastatic colorectal tumors and advanced gastrointestinal carcinomas. ${ }^{20,21}$ Initially, to optimize the number of fluorophores coupled to the A5B7, we conjugated $1,2,3$, or 6 of the nonradioactive reference compound per A5B7 molecule under mild basic conditions. As too many fluorophores were coupled to the antibody, this could have a detrimental effect on binding affinity, promote antibody aggregation, and reduce the strength of fluorescence through self-quenching. It became apparent that coupling of two fluorophores per A5B7 antibody emitted the strongest fluorescence. Moreover, this dual labeled A5B7 has similar $\mathrm{EC}_{50}$ and HPLC retention time to the native antibody, indicating that its binding affinity was preserved and that no antibody aggregation took place. When incubated with the CEA-expressing SW1222 cells, the cells were stained with bright-green fluorescence. This was largely blocked by the native A5B7 antibody, demonstrating the specific binding of the dual labeled A5B7 to the CEA in live cells. Furthermore, intense green fluorescence was observed in an SW1222 tumor xenograft tissue section stained with the dual labeled A5B7, indicating that it could illuminate the SW1222 tumor xenograft in the ex vivo fluorescence imaging for accurate tumor resection.

Encouraged by these in vitro results, we investigated the biodistribution of the ${ }^{124}$ I-Green dual labeled A5B7 in the SW1222 tumor xenograft mouse model at 24,48 , and $72 \mathrm{~h}$ post-iv injection. The high tumor uptake and low uptake in thoracoabdominal organs was similar to that previously reported for the directly labeled ${ }^{131}$ I-A5B7. ${ }^{16,19}$ The initially high blood pool and small intestine uptake observed at 24 and $48 \mathrm{~h}$, clearing to background levels at $72 \mathrm{~h}$, were in good agreement with the biodistribution pattern of a full size antibody. To demonstrate the translational potential of the ${ }^{124} \mathrm{I}$ Green dual labeled A5B7 for the cancer PET imaging and fluorescence-guided surgery, we carried out three sequential PET/CT scans of SW1222 tumor xenograft-bearing mice at 24, 48 , and $72 \mathrm{~h}$ post-iv injection followed by ex vivo fluorescence imaging. The tumor xenografts were clearly visualized at all three time points, reflecting the high affinity and specificity of the ${ }^{124}$ I-Green dual labeled A5B7 for CEA. Furthermore, uneven distribution of the radioactivity was observed in the tumor xenografts from the PET images, probably due to the heterogeneity of these tumors. In addition, significant thyroid uptake was observed in the PET images, most likely because of the catabolism of the ${ }^{124} \mathrm{I}$-Green dual labeled A5B7, generating free iodine-124 which subsequently accumulated in the thyroid. It was noted that the thyroid uptake increased over time, while the tumor, liver, and kidney levels gradually decreased. It expected that this thyroid uptake can be blocked by feeding the animals with $0.1 \%$ potassium iodide solution. ${ }^{19}$ Some radioactivity was also observed in the hearts in the $24 \mathrm{~h}$ PET images, owing to blood pool activity, but this had largely cleared by the 48 and $72 \mathrm{~h}$ PET images. The largest ratio of uptake by tumor compared to blood and other thoracoabdominal organs was observed at $72 \mathrm{~h}$ post-iv injection in the biodistribution study. Consequently, we decided to carried out the ex vivo fluorescence imaging at this time point in order to obtain the optimal tumor-to-background contrast. Indeed, tumor xenografts were clearly visualized and exhibited a clear boundary with the surrounding tissue, which facilitated complete resection of the tumor. When compared with other major thoracoabdominal organs, the tumor xenografts emitted the strongest fluorescence apart from the stomach and the large intestine. Much of the strong fluorescence from the stomach and large intestine appeared to arise from food and fecal residue. However, the ${ }^{124} \mathrm{I}-\mathrm{Green}$ dual labeled antibody may also be partially eliminated through the gut, contributing to some of this background fluorescence. In the control experiments by treating two healthy animals with either native or dual labeled A5B7, the ex vivo fluorescence images at $72 \mathrm{~h}$ post-iv injection showed identical high fluorescence from the stomach food and large intestine feces (Supporting Information, Figure S5). In addition, tumor uptake was nearly 11 and 6 times greater than stomach and large intestine, respectively, at this time point in the biodistribution study. Thus, it indicates the majority of fluorescence was from the food and feces residue. This strong autofluorescence is not expected to be a problem in the clinical setting as all patients would be fasting and subject to preoperative bowel preparation to ensure that the colon is empty. Future development of the dual labeling reagent with a near-infrared fluorophore such as the indocyanine green would further minimize the background fluorescence. In addition, we also performed sequential autoradiography and fluorescence imaging with the same tumor tissue sections prepared using the xenografts from $\mathrm{PET} / \mathrm{CT}$ and ex vivo fluorescence imaging. The distribution patterns of the radioactivity and fluorescence in these tumor sections were largely identical, which further confirmed that the observed radioactivity signals and green fluorescence in the tumors were from ${ }^{124}$ I-Green. Detection of deeper tumor lesions during fluorescence-guided surgery is challenging due to the limited tissue penetration of fluorescence; ${ }^{22}$ in this context, an added advantage of our ${ }^{124} \mathrm{I}$-Green is that it would enable the complementary use of an intraoperative radioactivity detector to map the gross locations of the tumors, followed by real-time fluorescence imaging to define the surgical margins and guide complete tumor resection.

We have developed a generic dual PET and fluorescent labeling reagent, ${ }^{124} \mathrm{I}$-Green. This approach enables a one-step installation of an iodine-124/fluorescein dual reporter to any antibody. When coupled with the CEA specific antibody A5B7, the affinity of the dual labeled A5B7 was preserved. In vitro 
fluorescence imaging of CEA overexpressing SW1222 cells indicated the specific binding of the dual labeled A5B7 to its antigens. The SW1222 xenografts in nude mice were clearly visualized by both PET/CT and ex vivo fluorescence imaging with excellent target-to-background contrast. These data demonstrate the feasibility of ${ }^{124} \mathrm{I}-\mathrm{Green}$ as a generic tool to label cancer-specific antibodies for malignant tumor PET imaging and fluorescence-guided surgery, prompting further translational research toward clinical application.

\section{EXPERIMENTAL SECTION}

Synthetic Chemistry and Radiochemistry. General Information. ${ }^{1} \mathrm{H}$ and ${ }^{13} \mathrm{C}$ NMR spectra were recorded at $\mathrm{rt}$ on a Bruker Avance 400 instrument operating at the frequency of $400 \mathrm{MHz}$ for ${ }^{1} \mathrm{H}$ and 100 $\mathrm{MHz}$ for ${ }^{13} \mathrm{C}$. Chemical shifts are reported in ppm relative to DMSO $(\sigma 2.48, \mathrm{~m})$ or $\mathrm{CH}_{3} \mathrm{CN}(\sigma 1.94, \mathrm{~s})$, and coupling constants $(J)$ are given in hertz. HPLC analysis was performed with an Agilent 1200 HPLC system equipped with a 1200 series diode array detector and a 1200 series fluorescence detector (G1321A). The chemical purity of the nonradioactive reference compound of ${ }^{124} \mathrm{I}-\mathrm{Green}$ was determined using HPLC, and it is greater than 95\% (Supporting Information, Figure S2). Radio-HPLC analysis was performed with an Agilent 1200 HPLC system equipped with a series diode array detector and Raytest GABI Star radioactivity detector. Reductant-free $\left[{ }^{125} \mathrm{I}\right] \mathrm{NaI}$ was purchased from PerkinElmer (product no. NEZ033L020MC) in $1 \times$ $10^{-5} \mathrm{M} \mathrm{NaOH}(\mathrm{pH} 8-11)$ aqueous solution. Reductant-free $\left[{ }^{124} \mathrm{I}\right] \mathrm{NaI}$ was purchased from PerkinElmer (product no. NEZ309) in $0.02 \mathrm{M}$ $\mathrm{NaOH}(\mathrm{pH} \mathrm{14})$ aqueous solution. All reagents were purchased from Sigma-Aldrich and were used without further purification. The radiochemical purity of the ${ }^{124} \mathrm{I}$-Green was determined by radioHPLC, and it is greater than 95\% (Supporting Information, Figure S2).

N-Propargyl-5(6)-carboxyfluoresceinamide [1]. A solution of $5(6)$-carboxyfluorescein $(500 \mathrm{mg}, 1.33 \mathrm{mmol})$ in DMF $(16 \mathrm{~mL})$ was cooled to $0{ }^{\circ} \mathrm{C}$ using an ice bath under an atmosphere of nitrogen. $\mathrm{N}, \mathrm{N}$-diisopropylethyl amine $(0.93 \mathrm{~mL}, 5.31 \mathrm{mmol})$ was added dropwise, and the solution was stirred for $20 \mathrm{~min}$. A $50 \%$ solution of propylphosphonic anhydride in ethyl acetate $(3.96 \mathrm{~mL}, 6.55 \mathrm{mmol})$ was then added dropwise to the reaction and followed by addition of propargylamine $(127 \mu \mathrm{L}, 1.99 \mathrm{mmol})$. The resulting solution was stirred at $0{ }^{\circ} \mathrm{C}$ for $1 \mathrm{~h}$ and allowed to warm to room temperature overnight. The reaction was quenched by addition of $1.0 \mathrm{M} \mathrm{HCl}(70$ $\mathrm{mL})$ and was extracted with ethyl acetate $(3 \times 30 \mathrm{~mL})$. The organic layer was washed with brine $(70 \mathrm{~mL})$ and then dried over $\mathrm{MgSO}_{4}$. The solvent was removed under vacuum, and the crude material was purified by flash chromatography on silica gel using ethyl acetate (with $0.1 \%$ acetic acid) as eluent. The title compound was obtained as an orange solid (165 mg, 30\%). ${ }^{1} \mathrm{H}$ NMR (400 MHz, DMSO- $\left.d_{6}\right) \delta 10.18$ $(\mathrm{s}, 2 \mathrm{H}, \mathrm{OH}), 9.32(\mathrm{t}, 3 / 5 \mathrm{H}, J=6 \mathrm{~Hz}, \mathrm{NH}), 9.16(\mathrm{t}, 2 / 5 \mathrm{H}, J=6 \mathrm{~Hz}$, $\mathrm{NH}), 8.47$ (s, 3/5H, ArH), 8.24 (d, 3/5H, $J=8 \mathrm{~Hz}, \operatorname{ArH}), 8.16$ (d, 2/ $5 \mathrm{H}, J=8 \mathrm{~Hz}, \mathrm{ArH}), 8.07(\mathrm{~d}, 2 / 5 \mathrm{H}, J=8 \mathrm{~Hz}, \mathrm{ArH}), 7.70(\mathrm{~s}, 2 / 5 \mathrm{H}$, $\mathrm{ArH}), 7.38$ (d, 3/5H, $J=8 \mathrm{~Hz}, \mathrm{ArH}), 6.67(\mathrm{~m}, 2 \mathrm{H}, \mathrm{ArH}), 6.60-6.52$ (m, $4 \mathrm{H}, \mathrm{ArH}), 4.11\left(\mathrm{dd}, 6 / 5 \mathrm{H}, J=6 \mathrm{~Hz}, 3 \mathrm{~Hz}, \mathrm{CH}_{2}\right), 3.99$ (dd, 4/5H, $\left.J=6 \mathrm{~Hz}, 3 \mathrm{~Hz}, \mathrm{CH}_{2}\right), 3.18\left(\mathrm{~s}, 3 / 5 \mathrm{H}, J=3 \mathrm{~Hz}, \mathrm{C}_{\mathrm{sp}} \mathrm{H}\right), 3.10(\mathrm{~s}, 2 / 5 \mathrm{H}, J$ $\left.=3 \mathrm{~Hz}, \mathrm{C}_{\mathrm{sp}} \mathrm{H}\right) .{ }^{13} \mathrm{C}$ NMR $\left(100 \mathrm{MHz}, \mathrm{DMSO}-d_{6}\right) \delta 168.1,167.9,164.3$, $164.2,159.6,154.9,152.7,151.8,139.8,135.5,135.4,134.7,129.5$, 129.2 , 128.4, 127.5, 126.5, 124.9, 124.3, 123.4, 122.4, 112.7, 112.6, $109.1,108.9,102.2,80.9,80.7,73.1,28.7,28.6$. HRMS (EI, $m / z)[\mathrm{M}+$ $\mathrm{H}]$ : calcd 414.0972 for $\mathrm{C}_{24} \mathrm{H}_{16} \mathrm{NO}_{6}^{+}$, found 414.0978 .

$\mathrm{N}$-[1-(4-N'-Succinimidyl)benzyl-5-iodo-1H-[1,2,3]triazol-4-yl]methyl-5(6)-carboxyfluoresceinamide [Nonradioactive Reference Compound of ${ }^{124}$ I-Green]. To a solution of copper(I) iodide (18.4 $\mathrm{mg}, 96.76 \mu \mathrm{mol})$ and triethyl amine $(6.5 \mu \mathrm{L}, 48.38 \mu \mathrm{mol})$ in anhydrous DMF $(1.8 \mathrm{~mL})$ was added the $N$-propargyl-5(6)carboxyfluoresceinamide (synthetic method in Supporting Information) $(20.0 \mathrm{mg}, 48.38 \mu \mathrm{mol})$, 4-azidomethyl- $N$-succinimidyl benzoate $(13.2 \mathrm{mg}, 48.38 \mu \mathrm{mol})$, and $N$-iodosuccinimide $(12.0 \mathrm{mg}, 53.33 \mu \mathrm{mol}$, 1.1 equiv). The resulting mixture was stirred under an atmosphere of argon at $\mathrm{rt}$ overnight. The reaction was quenched with water $(15 \mathrm{~mL})$ and extracted with ethyl acetate $(3 \times 10 \mathrm{~mL})$. The organic layer was dried over $\mathrm{MgSO}_{4}$, and the solvent was removed under vacuum. The resulting crude material was purified by flash column chromatography on silica, eluting with $\mathrm{DCM} /$ methanol/AcOH (9/1/0.1) to yield the title compound as an orange solid (14.5 mg, 37\%). The HPLC retention times were 26.7 and $27.6 \mathrm{~min}$ for the two regioisomers, respectively, using a ZORBAX column (300SB-C18, $9.4 \mathrm{~mm} \times 250$ $\mathrm{mm}, 5 \mu \mathrm{m})$ with the following eluent: water $(0.1 \%$ formic acid) as solvent $\mathrm{A}$ and methanol ( $0.1 \%$ formic acid) as solvent $\mathrm{B}$, going from $30 \%$ B to $60 \%$ of B in 25 min then to $90 \%$ B in 5 min and going back to $30 \% \mathrm{~B}$ in $10 \mathrm{~min}$ and remaining at $30 \% \mathrm{~B}$ for an additional $10 \mathrm{~min}$ with a flow rate of $3.0 \mathrm{~mL} / \mathrm{min} .{ }^{1} \mathrm{H}$ NMR $\left(400 \mathrm{MHz}, \mathrm{CH}_{3} \mathrm{CN}-d_{3}\right) \delta$ 8.34 (s, 4/5H, ArH), 8.15 (d, 4/5H, $J=9 \mathrm{~Hz}, \operatorname{ArH}), 8.09$ (d, 6/5H, $J=$ $8 \mathrm{~Hz}, \mathrm{ArH}), 8.06(\mathrm{~d}, 6 / 5 \mathrm{H}, J=9 \mathrm{~Hz}, \mathrm{ArH}), 7.68(\mathrm{~s}, 1 \mathrm{H}, \mathrm{NH}), 7.38$ (d, $6 / 5 \mathrm{H}, J=8 \mathrm{~Hz}, \mathrm{ArH}), 7.26(\mathrm{~d}, 2 \mathrm{H}, J=9 \mathrm{~Hz}, \operatorname{ArH}), 7.25$ (d, 4/5H, $J=$ $8 \mathrm{~Hz}, \mathrm{ArH}), 6.69(\mathrm{~s}, 2 \mathrm{H}, \mathrm{ArH}), 6.63(\mathrm{~d}, 2 \mathrm{H}, J=9 \mathrm{~Hz}, \mathrm{ArH}), 6.53(\mathrm{~d}$, $2 \mathrm{H}, J=9 \mathrm{~Hz}, \mathrm{ArH}), 5.74\left(\mathrm{~s}, 6 / 5 \mathrm{H}, \mathrm{NCH}_{2}\right), 5.68\left(\mathrm{~s}, 4 / 5 \mathrm{H}, \mathrm{NCH}_{2}\right)$, $4.66\left(\mathrm{~d}, 6 / 5 \mathrm{H}, J=6 \mathrm{~Hz}, \underline{\mathrm{C}}_{2}-\mathrm{NH}\right), 4.50\left(\mathrm{~d}, 4 / 5 \mathrm{H}, J=6 \mathrm{~Hz}, \mathrm{C}_{2}-\right.$ $\mathrm{NH}), 2.84\left(\mathrm{~s}, 4 \mathrm{H}, \mathrm{CH}_{2}-\mathrm{CH}_{2}\right) .{ }^{13} \mathrm{C}$ NMR $\left(100 \mathrm{MHz}, \mathrm{DMSO}-d_{6}\right) \delta$ $179.4,170.2,168.1,164.5,164.3,162.3,161.4,159.7,151.8,148.5$, $148.4,143.2,143.0,135.8,134.8,130.5,129.2,129.1,128.7,128.3$, $126.5,124.9,124.0,123.6,112.7,109.0,102.2,83.9,52.8,48.6,35.8$, 35.4, 30.7, 29.5, 25.5, 25.2. HRMS (EI, $m / z)[\mathrm{M}+\mathrm{H}]$ : calcd 814.0641 for $\mathrm{C}_{36} \mathrm{H}_{25} \mathrm{IN}_{5} \mathrm{O}_{10}{ }^{+}$, found 814.0662.

Radiolabeling. For ${ }^{125}$-Labeling. Copper(II) chloride $(3.4 \mathrm{mg}$, $25.3 \mu \mathrm{mol})$, triethylamine $(5.3 \mu \mathrm{L}, 38.1 \mu \mathrm{mol}, 1.5$ equiv), and bathophenanthroline $(850 \mu \mathrm{g}, 2.5 \mu \mathrm{mol}, 10 \mathrm{~mol} \%)$ were mixed in anhydrous acetonitrile $(500 \mu \mathrm{L})$. The resulting suspension $(62.5 \mu \mathrm{L})$ was added to $\mathrm{N}$-propargyl-5(6)-carboxyfluoresceinamide (1.4 mg, 3.1 $\mu \mathrm{mol})$ in anhydrous DMF $(62.5 \mu \mathrm{L})$. The resulting red suspension (40 $\mu \mathrm{L}$ ) was added to a mixture of 4-azidomethyl- $\mathrm{N}$-succinimidyl benzoate $(226 \mu \mathrm{g}, 1.0 \mu \mathrm{mol})$ in acetonitrile $(20 \mu \mathrm{L})$ and $\left[{ }^{125} \mathrm{I}\right] \mathrm{NaI}(\sim 10 \mathrm{MBq})$ in $1 \times 10^{-5} \mathrm{M} \mathrm{NaOH}$ solution $(6.0 \mu \mathrm{L})$.

For ${ }^{124}$ /-Labeling. Copper(II) chloride $(3.4 \mathrm{mg}, 25.3 \mu \mathrm{mol})$, triethylamine ( $4.4 \mu \mathrm{L}, 31.5 \mu \mathrm{mol}, 1.38$ equiv), and bathophenanthroline $(850 \mu \mathrm{g}, 2.5 \mu \mathrm{mol}, 10 \% \mathrm{~mol})$ were mixed in anhydrous acetonitrile $(500 \mu \mathrm{L})$. The resulting suspension $(62.5 \mu \mathrm{L})$ was added to $N$-propargyl-5(6)-carboxyfluoresceinamide (1.4 mg, 3.1 $\mu \mathrm{mol})$ in anhydrous DMF $(62.5 \mu \mathrm{L})$. The resulting red suspension $(40 \mu \mathrm{L})$ was added to a mixture of 4-azidomethyl- $N$-succinimidyl benzoate $(226 \mu \mathrm{g}, 1.0 \mu \mathrm{mol})$ and triethylamine hydrochloride (TEA. $\mathrm{HCl})(16.5 \mu \mathrm{g}, 0.12 \mu \mathrm{mol})$ in acetonitrile $(20 \mu \mathrm{L})$ and $\left[{ }^{124} \mathrm{I}\right] \mathrm{NaI}(\sim 12$ $\mathrm{MBq})$ in $0.02 \mathrm{M} \mathrm{NaOH}$ solution $(6.0 \mu \mathrm{L})$.

After incubation at $\mathrm{rt}$ for $90 \mathrm{~min}$, the reaction mixture was quenched with DMSO $(100 \mu \mathrm{L})$ followed by water/MeOH $(4: 1,1.0 \mathrm{~mL})$. The resulting solution was purified by HPLC using a ZORBAX column (300SB-C18, $9.4 \mathrm{~mm} \times 250 \mathrm{~mm}, 5 \mu \mathrm{m}$ ) with the following eluent: water as solvent $\mathrm{A}$ and methanol ( $0.1 \%$ formic acid) as solvent $\mathrm{B}$, going from $30 \% \mathrm{~B}$ to $60 \% \mathrm{~B}$ in $25 \mathrm{~min}$ then to $90 \% \mathrm{~B}$ in $5 \mathrm{~min}$ and going back to $30 \% \mathrm{~B}$ in $10 \mathrm{~min}$ and remaining at $30 \% \mathrm{~B}$ for an additional $10 \mathrm{~min}$ with a flow rate of $3.0 \mathrm{~mL} / \mathrm{min}$. The retention time of the title compounds were 26.8 and $27.7 \mathrm{~min}$ for the two regioisomers, respectively. ${ }^{124} \mathrm{I}$-Green was co-eluted with the nonradioactive reference compound using the same HPLC method to confirm its identity. Formulation: ${ }^{124}$ I-Green HPLC eluent was diluted to $15 \% \mathrm{MeOH}$ in water and was loaded on a preconditioned Waters C-18 light Sep-Pak cartridge [washing with $\mathrm{MeOH}(5 \mathrm{~mL})$ and followed by water $(5 \mathrm{~mL})]$. After washing with water $(5 \mathrm{~mL}),{ }^{124} \mathrm{I}$ Green was released using EtOH. The EtOH was removed with a stream of nitrogen and ${ }^{124} \mathrm{I}$-Green was then redissolved in DMSO for further use.

Antibody A5B7 Conjugation. The murine anti-CEA antibody A5B7 $7^{16}(400 \mu \mathrm{L}, 3.9 \mathrm{mg} / \mathrm{mL})$ in $\mathrm{pH} 7.4$ PBS was buffer exchanged prior to conjugation on a PD-10 minitrap G-25 size exclusion column (GE healthcare) eluting with $10 \mathrm{mM}, \mathrm{pH} 9.0$ carbonate buffer. The most concentrated fractions $(200-800 \mu \mathrm{L})$ excluding the loading volume were collected and the concentration of the resulting antibody was determined as $2.2 \mathrm{mg} / \mathrm{mL}$ by Bradford protein assay with the Pierce Coomassie (Bradford) Protein Assay Kit at absorbance $595 \mathrm{~nm}$.

${ }^{124} \mathrm{I}$-Green $(5.0 \mathrm{MBq})$ in DMSO $(2.5 \mu \mathrm{L})$ and the nonradioactive reference compound $(0,2,5,10$, or 20 equiv. to the A5B7, 
respectively) in DMSO $(2.5 \mu \mathrm{L})$ were added to the antibody A5B7 $(100 \mu \mathrm{L}, 2.2 \mathrm{mg} / \mathrm{mL})$ in $10 \mathrm{mM}, \mathrm{pH} 9.0$ carbonate buffer. The resulting solution was incubated in the dark at $\mathrm{rt}$ for $45 \mathrm{~min}$. The reaction was diluted to a total volume of $500 \mu \mathrm{L}$ using $\mathrm{pH}$ 7.4 PBS and was purified on a PD-10 minitrap G-25 size exclusion column (GE healthcare) eluting with $\mathrm{pH} 7.4$ PBS. The fractions $(200-700 \mu \mathrm{L})$ containing the dual labeled antibody A5B7 were collected. The purified A5B7 was submitted to HPLC analysis with a Phenomenex size exclusion column (BioSep-SEC-S3000) eluting with PBS-EDTA/ water $1: 1$ using a flow rate of $5.0 \mathrm{~mL} / \mathrm{min}$ in $20 \mathrm{~min}$ with a UV detection at $280 \mathrm{~nm}$. Fluorescence emission spectra between 508 and $572 \mathrm{~nm}$ of each of the dual labeled A5B7 antibodies $(50 \mu \mathrm{g})$ was measured using the fluorescence detector in an Agilent 1200 HPLC system with an excitation wavelength of $460 \mathrm{~nm}$. The antibody recovery rate from the $\mathrm{PD}-10$ column was determined by loading the dual labeled A5B7 $(50 \mathrm{KBq}, 500 \mu \mathrm{L})$ on a PD-10 column and eluted with $\mathrm{pH}$ 7.4 PBS. The radioactive fractions were collected and measured with a Raytest GABI star radioactivity detector. The antibody recovery rate was $80 \pm 4 \%(n=3)$. The average fluorophore(s) per antibody was then calculated based on the following equation:

Average fluorophore(s) per antibody $=$ labeling efficiency $\times$ equivalents of added nonradioactive reference compound of dual labeling reagent/recovery efficiency of dual labeled antibody from the PD-10 column

ELISA Assay to Measure the $\mathrm{EC}_{50}$ of the Dual Labeled A5B7 with CEA. A 96-well plate was coated with carcinoembryonic antigen (CEA) at $10 \mu \mathrm{g} / \mathrm{mL}$ in PBS $(100 \mu \mathrm{L})$ at $4{ }^{\circ} \mathrm{C}$ for $24 \mathrm{~h}$. The plate was washed with PBS and blocked with $5 \%$ marvel/PBST $(150 \mu \mathrm{L})$ at $\mathrm{rt}$ for $1 \mathrm{~h}$. Serial dilutions of the dual labeled or native A5B7 $(100 \mu \mathrm{L}$, $0.03 \mathrm{nM}, 0.14 \mathrm{nM}, 0.70 \mathrm{nM}, 3.0 \mathrm{nM}, 19.2 \mathrm{nM}, 96.0 \mathrm{nM}, 480.0 \mathrm{nM}, 2.4$ $\mu \mathrm{M}$, and $8.3 \mu \mathrm{M}$ ) were added to the plate and incubated at $\mathrm{rt}$ for $2 \mathrm{~h}$. The plate was washed with PBS Tween-20 and deionized water, after which the sheep antimouse-horseradish peroxidase-IgG $(100 \mu \mathrm{L})$ was added and incubated at $\mathrm{rt}$ for another $1 \mathrm{~h}$. The samples were then washed with PBS Tween-20 and deionized water. O-Phenylenediamine dihydrochloride solution $(100 \mu \mathrm{L})$ was added to the samples, and color was developed in 5-10 min before addition of $\mathrm{HCl}(100 \mu \mathrm{L}$, $4.0 \mathrm{M}$ ). The absorbance was then read at $490 \mathrm{~nm}$. The experiments were repeated three times. The data were analyzed using GraphPad Prism 7 software.

Cell Line. The human CEA-producing colorectal adenocarcinoma cell line SW1222 was obtained from the European Collection of Cell Cultures. ${ }^{16}$ Cells were cultured in DMEM medium supplemented with $10 \% \mathrm{FBS}, 200 \mathrm{U} / \mathrm{L}$ penicillin, $0.1 \mathrm{~g} / \mathrm{L}$ streptomycin, and $2 \mathrm{mM} \mathrm{L}-$ glutamine at $37^{\circ} \mathrm{C}$ under humidified atmosphere containing $5 \% \mathrm{CO}_{2}$.

Tumor Xenograft Model. The human colorectal adenocarcinoma cell line SW1222 was used to develop a subcutaneous xenograft model by injecting $5 \times 10^{6}$ cells in $100 \mu \mathrm{L}$ of saline into the front left flanks of 4 week old female CD1 nude mice. The CEA expression in the SW1222 tumor xenografts was previously quantified as $22-70 \mu \mathrm{g} / \mathrm{g}$ tumor. ${ }^{16}$ Tumor volume was estimated using the formula $V=(L \times W$ $\times H) / 2$ and the xenograft was established within 2 weeks. All animal experiments complied with the Animals (Scientific Procedures) Act (UK 1986) and Home Office (UK) guidelines and were conducted under a Home Office license (P9C94E8A4) with local ethical approval by the KCL College Research Ethics Committee (CREC).

In Vitro SW1222 Cell Staining and Blocking Study. SW1222 cells $\left(1 \times 10^{6}\right)$ were plated on a 6-well plate and incubated in the cell culture media for $18 \mathrm{~h}$. The medium was then removed, and the adherent cells were washed twice with PBS $(2.0 \mathrm{~mL})$. The dual labeled A5B7 $(7 \mu \mathrm{g} / \mathrm{mL})$ in PBS $(1.0 \mathrm{~mL})$ was added, followed by addition of either the native A5B7 solution $(10 \mu \mathrm{L}, 3.9 \mathrm{mg} / \mathrm{mL})$ to three wells for blocking study or PBS $(10 \mu \mathrm{L})$ to the remaining three wells. The cells were incubated for $1 \mathrm{~h}$ at $37{ }^{\circ} \mathrm{C}, 5 \% \mathrm{CO}_{2}$. Bisbenzimide $\mathrm{H} 33342$ (Hoechst 33342) (10 $\mu \mathrm{L}, 0.25 \mathrm{mM})$ was then added $5 \mathrm{~min}$ before the end of the incubation period. Subsequently, the solution was removed and the cells were washed twice with ice-cold PBS $(2.0 \mathrm{~mL})$ before being viewed under a digital inverted fluorescence microscope EVOS $\mathrm{fl}$
(40× objective, AMG, USA) and the default light cubes GFP and DAPI were selected for fluorescein and Hoechst, respectively.

Immunofluorescence Imaging. Frozen SW1222 tumor xenograft sections $(10 \mu \mathrm{m})$ were fixed in acetone for $10 \mathrm{~min}$ at $\mathrm{rt}$, incubated in $3 \%$ normal serum/PBS for $30 \mathrm{~min}$, and then incubated with the dual labeled A5B7 $(5 \mu \mathrm{g} / \mathrm{mL})$ for another $30 \mathrm{~min}$. Hoechst $33342(10 \mu \mathrm{L}$, $0.25 \mathrm{mM}$ ) was then added $5 \mathrm{~min}$ before the end of the incubation period. After rinsing with PBS, sections were mounted in PBS and viewed under a digital inverted fluorescence microscope EVOS $\mathrm{fl}(4 \times$ objective, AMG, USA) and the default light cubes GFP and DAPI were selected for fluorescein and Hoechst, respectively.

Dual Labeled A5B7 Biodistribution Studies. CD1 nude mice bearing established SW1222 tumor xenografts were intravenously injected with approximately $0.8 \mathrm{MBq}$ of the ${ }^{124} \mathrm{I}$-Green dual labeled A5B7 $(\sim 44 \mu \mathrm{g})$ in $100 \mu \mathrm{L}$ of PBS. The mice $(n=3)$ were culled by cervical dislocation at 24,48 , and $72 \mathrm{~h}$ post-iv injection, respectively. The tumor xenograft, major thoracoabdominal organs, left femur, and thigh muscle were harvested, weighed, and gamma-counted. The radioactivity in each organ was expressed as $\% \mathrm{ID} / \mathrm{g}$. The total injected dose was defined as the sum of the whole body counts excluding the tail.

PET/CT and Ex Vivo Fluorescence Imaging. Preclinical PET/ CT images were acquired using a NanoScan PET/CT (Mediso, Budapest, Hungary) scanner with mice under isoflurane (2\% in oxygen) anesthesia. The SW1222 tumor xenograft-bearing CD1 nude mice $(n=3)$ each received approximately $0.8 \mathrm{MBq}$ of the ${ }^{124} \mathrm{I}$-Green dual labeled A5B7 $(\sim 44 \mu \mathrm{g})$ in PBS $(100 \mu \mathrm{L})$ via iv injection. PET scanning was performed for $60 \mathrm{~min}$ at 24,48 , and $72 \mathrm{~h}$ postinjection followed by a CT scan. All PET/CT data were reconstructed with the Monte Carlo-based full-3D iterative algorithm Tera-Tomo (Mediso Medical Imaging Systems, Budapest, Hungary). Raw PET data were reconstructed into $60 \mathrm{~min}$ bins using reconstruction settings (four iterations, six subsets, $0.4 \times 0.4 \times 0.4 \mathrm{~mm}^{3}$ voxel size) as well as intercrystal scatter correction. All reconstructed data were analyzed with VivoQuant software (v3.0, inviCRO, LLC, Boston, USA). All three animals were culled by cervical dislocation at the end of the last $\mathrm{PET} / \mathrm{CT}$ scan. The skin surrounding the front left flanks was removed to expose the tumor xenografts. Fluorescence images were taken using a FOBI $(\mathrm{tm}) \mathrm{BGRN}$ fluorescent imaging system (Neoscience, Suwon, Republic of Korea) both before and after the tumor resection. Subsequently, the tumor xenografts, major thoracoabdominal organs, and thigh muscle were harvested for fluorescence imaging with the FOBI fluorescence imaging system with an excitation wavelength of $460 \mathrm{~nm}$. All fluorescence images were taken using LUCAM capture software.

Ex Vivo Autoradiography and Fluorescence Imaging. Three cryosections (5 $\mathrm{m}$ thick) were prepared from the SW1222 tumor xenografts collected 1 week after the PET/CT and ex vivo fluorescence imaging. These were allowed to air-dry and then exposed to a phosphor screen (Molecular Dynamics) for 3 days. The phosphor screen was scanned in a Typhoon 8600 phosphor imager at a resolution of $50 \mu \mathrm{m}$. The same three tumor sections from the autoradiography were then used for fluorescence imaging in the same imager with the default emission filter setting for fluorescein (fluorescein $526 \mathrm{SP}$ ) with green laser $(532 \mathrm{~nm}$ ) at high sensitivity with a resolution of $50 \mu \mathrm{m}$. All images were analyzed using ImageJ software (v1.50i, NIH, USA)

\section{ASSOCIATED CONTENT}

\section{Supporting Information}

The Supporting Information is available free of charge on the ACS Publications website at DOI: 10.1021/acs.jmedchem.7b01746.

A5B7 labeling efficiency and the average fluorophores per antibody; HPLC chromatograms including the crude radioiodination mixture of ${ }^{124} \mathrm{I}$-Green, ${ }^{124} \mathrm{I}$-Green coeluting with its nonradioactive reference compound, and dual labeled and native A5B7; ${ }^{124} \mathrm{I}-$ Green dual labeled 
A5B7 biodistribution data; radioactivity accumulation in selected organs extracted from the PET scans; ex vivo fluorescence imaging with healthy $\mathrm{CD} 1$ nude mice; ${ }^{1} \mathrm{H}$ and ${ }^{13} \mathrm{C}$ NMR spectra for all compounds prepared (PDF)

Molecular formula strings (CSV)

\section{AUTHOR INFORMATION}

\section{Corresponding Authors}

*For R.Y.: phone, 00442071889613; E-mail, ran.yan@kcl.ac.uk. *For Z.L.: phone, 008641184394963; E-mail, luzhi712@163. com; address, Department of Nuclear Medicine, the First Affiliated Hospital of Dalian Medical University, 116020 People's Republic of China.

ORCID $\odot$

Ran Yan: 0000-0002-0303-3196

\section{Author Contributions}

Zhi Lu and Truc Thuy Pham contributed equally to this work. The manuscript was written through contributions of all authors. All authors have given approval to the final version of the manuscript.

\section{Notes}

The views expressed are those of the authors and not necessarily those of the NHS, the NIHR, or the DoH. PET scanning equipment was funded by an equipment grant from the Wellcome Trust.

The authors declare no competing financial interest.

\section{ACKNOWLEDGMENTS}

Dr Ran Yan thanks Bioprobe UK Ltd. for providing the FOBI fluorescence imaging system. Zhi Lu thanks the Scientific Study Project for Institutes of Higher Learning, Ministry of Education, Liaoning Province (L2015149), China for support of this work. Truc Thuy Pham thanks Rosetrees Trust Ph.D. studentship (M545) for support of this work and Dr. Jayanta Bordoloi's help with the development of animal model, in vivo PET imaging, and data analysis. The research was funded/ supported by the National Institute for Health Research (NIHR) Biomedical Research Centre based at Guy's and St. Thomas' NHS Foundation Trust and King's College London, the Wellcome/EPSRC Centre for Medical Engineering at King's College London (WT 203148/Z/16/Z), the King's College London and UCL Comprehensive Cancer Imaging Centre (C1519/A16463) funded by CRUK and EPSRC in association with the MRC and $\mathrm{DoH}$ (England), the Experimental Cancer Medicine Centre at King's College, and the King's Health Partners/King's College London Cancer Research UK Cancer Centre. The work undertaken at UCLH/ UCL was funded in part by the Department of Health's NIHR Biomedical Research Centres funding scheme.

\section{ABBREVIATIONS USED}

$\mathrm{Bq}$, becquerel; ccRCC, clear cell renal cell carcinoma; CEA, carcinoembryonic antigen; $\mathrm{CT}$, computed tomography; $\mathrm{EC}_{50}$, half-maximal effective concentration; ELISA, enzyme-linked immunosorbent assay; FDA, Food and Drug Administration; ${ }^{18} \mathrm{~F}$-FDG, 2-deoxy-2-[ $\left[{ }^{18} \mathrm{~F}\right]$ fluoro-D-glucose; HER2, growth factor receptor 2; ICG, indocyanine green; iv, intravenous; \% $\mathrm{ID} / \mathrm{g}$, percentage injected dose per gram tissue; NIS, $\mathrm{N}$ iodosuccinimide; PET, positron emission tomography; RCYs, radiochemical yields; rt, room temperature; TEA $\cdot \mathrm{HCl}$, triethylamine hydrochloride

\section{REFERENCES}

(1) Cancer; World Health Organization: Geneva, 2018; http://www. who.int/cancer/en/ (accessed October 22, 2017).

(2) Nguyen, Q. T.; Tsien, R. Y. Fluorescence-Guided Surgery with Live Molecular Navigation-A New Cutting Edge. Nat. Rev. Cancer 2013, 13 (9), 653-662.

(3) Kostakoglu, L.; Agress, H.; Goldsmith, S. J. Clinical Role of FDG PET in Evaluation of Cancer Patients. Radiographics 2003, 23 (2), $315-40$; quiz 533 ..

(4) Chang, J. M.; Lee, H. J.; Goo, J. M.; Lee, H. Y.; Lee, J. J.; Chung, J. K.; Im, J. G. False Positive and False Negative FDG-PET Scans in Various Thoracic Diseases. Korean J. Radiol. 2006, 7 (1), 57-69.

(5) Mestel, R. Cancer: Imaging with Antibodies. Nature 2017, 543 (7647), 743-746.

(6) van Dongen, G. A. M. S.; Visser, G. W. M.; Lub-de Hooge, M. N.; de Vries, E. G.; Perk, L. R. Immuno-PET: A Navigator in Monoclonal Antibody Development and Applications. Oncologist 2007, 12 (12), 1379-1389.

(7) Dijkers, E. C.; Oude Munnink, T. H.; Kosterink, J. G.; Brouwers, A. H.; Jager, P. L.; De Jong, J. R.; Van Dongen, G. A.; Schröder, C. P.; Lub-De Hooge, M. N.; De Vries, E. G. Biodistribution of ${ }^{89} \mathrm{Zr}-$ Trastuzumab and PET Imaging of HER2-Positive Lesions in Patients with Metastatic Breast Cancer. Clin. Pharmacol. Ther. 2010, 87 (5), 586-592.

(8) Divgi, C. R.; Uzzo, R. G.; Gatsonis, C.; Bartz, R.; Treutner, S.; Yu, J. Q.; Chen, D.; Carrasquillo, J. A.; Larson, S.; Bevan, P.; Russo, P. Positron Emission Tomography/Computed Tomography Identification of Clear Cell Renal Cell Carcinoma: Results from the REDECT Trial. J. Clin. Oncol. 2013, 31 (2), 187-194.

(9) Povoski, S. P.; Hall, N. C.; Murrey, D. A.; Sharp, D. S.; Hitchcock, C. L.; Mojzisik, C. M.; Bahnson, E. E.; Knopp, M. V.; Martin, E. W.; Bahnson, R. R. Multimodal Imaging and Detection Strategy with 124I-Labeled Chimeric Monoclonal Antibody cG250 for Accurate Localization and Confirmation of Extent of Disease during Laparoscopic and Open Surgical Resection of Clear Cell Renal Cell Carcinoma. Surg. Innov. 2013, 20 (1), 59-69.

(10) Van Dam, G. M.; Themelis, G.; Crane, L. M. A.; Harlaar, N. J.; Pleijhuis, R. G.; Kelder, W.; Sarantopoulos, A.; De Jong, J. S.; Arts, H. J. G.; Van Der Zee, A. G. J.; Bart, J.; Low, P. S.; Ntziachristos, V. Intraoperative Tumor-Specific Fluorescence Imaging in Ovarian Cancer by Folate Receptor- $\alpha$ Targeting: First in-Human Results. Nat. Med. 2011, 17 (10), 1315-1319.

(11) Hernandez, R.; Sun, H.; England, C. G.; Valdovinos, H. F.; Ehlerding, E. B.; Barnhart, T. E.; Yang, Y.; Cai, W. CD146-Targeted immunoPET and NIRF Imaging of Hepatocellular Carcinoma with a Dual-Labeled Monoclonal Antibody. Theranostics 2016, 6 (11), 19181933.

(12) Lütje, S.; Rijpkema, M.; Helfrich, W.; Oyen, W. J. G.; Boerman, O. C. Targeted Radionuclide and Fluorescence Dual-Modality Imaging of Cancer: Preclinical Advances and Clinical Translation. Mol. Imaging Biol. 2014, 16 (6), 747-755.

(13) An, F.; Chan, M.; Kommidi, H.; Ting, R. Dual PET and NearInfrared Fluorescence Imaging Probes as Tools for Imaging in Oncology. AJR, Am. J. Roentgenol. 2016, 207 (2), 266-273.

(14) Yan, R.; El-Emir, E.; Rajkumar, V.; Robson, M.; Jathoul, A. P.; Pedley, R. B.; Årstad, E. One-Pot Synthesis of an ${ }^{125}$ I-Labeled Trifunctional Reagent for Multiscale Imaging with Optical and Nuclear Techniques. Angew. Chem., Int. Ed. 2011, 50 (30), 6793-6795.

(15) Yan, R.; Sander, K.; Galante, E.; Rajkumar, V.; Badar, A.; Robson, M.; El-Emir, E.; Lythgoe, M. F.; Pedley, R. B.; Årstad, E. A One-Pot Three-Component Radiochemical Reaction for Rapid Assembly of ${ }^{125}$ I-Labeled Molecular Probes. J. Am. Chem. Soc. 2013, 135 (2), 703-709.

(16) El Emir, E.; Qureshi, U.; Dearling, J. L. J.; Boxer, G. M.; Clatworthy, I.; Folarin, A. A.; Robson, M. P.; Nagl, S.; Konerding, M. A.; Pedley, R. B. Predicting Response to Radioimmunotherapy from 
the Tumor Microenvironment of Colorectal Carcinomas. Cancer Res. 2007, 67 (24), 11896-11905.

(17) Fass, L. Imaging and Cancer: A Review. Mol. Oncol. 2008, 2 (2), $115-152$.

(18) Galante, E.; Schoultz, B. W.; Koepp, M.; Årstad, E. ChelatorAccelerated One-Pot "Click" Labeling of Small Molecule Tracers with 2-[ $\left[{ }^{18} \mathrm{~F}\right]$ fluoroethyl Azide. Molecules 2013, 18 (5), 5335-5347.

(19) Pedley, R. B.; Hill, S. A.; Boxer, G. M.; Flynn, A. A.; Boden, R.; Watson, R.; Dearling, J.; Chaplin, D. J.; Begent, R. H. J. Eradication of Colorectal Xenografts by Combined Radioimmunotherapy and Combretastatin A-4 3-O-Phosphate. Cancer Res. 2001, 61 (12), $4716-4722$.

(20) Lane, D. M.; Eagle, K. F.; Begent, R. H. J.; Hope-Stone, L. D.; Green, A. J.; Casey, J. L.; Keep, P. A.; Kelly, A. M. B.; Ledermann, J. A.; Glaser, M. G. Radioimmunotherapy of Metastatic Colorectal Tumours with Iodine-131-Labeled Antibody to Carcinoembryonic Antigen: Phase I/II Study with Comparative Biodistribution of Intact and F(ab́)2 Antibodies. Br. J. Cancer 1994, 70 (3), 521-525.

(21) Meyer, T.; Gaya, A. M.; Dancey, G.; Stratford, M. R. L.; Othman, S.; Sharma, S. K.; Wellsted, D.; Taylor, N. J.; Stirling, J. J.; Poupard, L.; Folkes, L. K.; Chan, P. S.; Pedley, R. B.; Chester, K. A.; Owen, K.; Violet, J. A.; Malaroda, A.; Green, A. J.; Buscombe, J.; Padhani, A. R.; Rustin, G. J.; Begent, R. H. A Phase I Trial of Radioimmunotherapy with ${ }^{131}$ I-A5B7 Anti-CEA Antibody in Combination with Combretastatin-A4-Phosphate in Advanced Gastrointestinal Carcinomas. Clin. Cancer Res. 2009, 15 (13), 4484-4492.

(22) Povoski, S. P.; Mojzisik, C. M.; Sullivan, B. J. Radioimmunoguided Surgery: Intraoperative Radioimmunodetection for the Radioguided Localization and Resection of Tumors. In Radioguided Surgery; Herrmann, K., Nieweg, O., Povoski, S., Eds.; Springer: Cham, Switzerland, 2016; pp 371-418. 